\title{
Analysis of Suitable Farm Size for Fattening Pon Yang Kham Cattle
}

\author{
Sitthinan Wiwatthanapornchai ${ }^{1}$ \\ ${ }^{1}$ Faculty of Natural Resources and Agro-Industry, Kasetsart University Chalermphrakiat Sakon Nakhon Province \\ Campus, Sakon Nakhon, Thailand \\ Correspondence: Sitthinan Wiwatthanapornchai, Faculty of Natural Resources and Agro-Industry, Kasetsart \\ University, Sakon Nakhon, Thailand. Tel: 66-9-56152635. E-mail: wiwattsitthinan@gmail.com, fnasnw@ku.ac.th
}

Received: December 27, 2018

doi:10.5539/mas.v13n7p107
Accepted: January 8, $2019 \quad$ Online Published: June 30, 2019

URL: https://doi.org/10.5539/mas.v13n7p107

\begin{abstract}
Pon Yang Kham Livestock Cooperative Limited (PYK Coop) is a local business organisation located in Sakon Nakhon province, Thailand. It has an essential economic role in assisting farmers and the community by creating a fair income distribution. However, PYK Coop has been facing problems from an oversupply of fattening cattle and the numbers involved in cattle production. This research investigated the costs and returns of production and the suitable farm size for beef cattle production to supply PYK Coop. The primary data were collected from 409 farmers in the cooperative using a questionnaire. The costs and returns of production were analysed and classified by the size of the farm to determine the most appropriate farm size for investment.

The results revealed that the average number of cattle for individual farmers was 10.10 consisting of 3.50 bulls and cows, 2.64 calves and growing cattle, and 3.50 feedlot cattle. The cost of cattle production was divided into variable and fixed costs, which ranged annually between THB 17,279.13 and THB 300,185.88. The total annual income was THB 274,836.43. The annual net return of production (total revenue minus cost) was THB 25,984.81, while the annual net return of production per head of cattle was THB 25,984.81. The optimal farm size for beef cattle for the cooperative was a medium-sized farm.

Overall, the results suggested that PYK Coop should encourage farmers to raise fattening cattle as a part-time occupation and aim to have no more than 10 head of cattle per farm. In doing so, PYK Coop should adjust the slaughter quota in accord with the number of beef cattle supplied by the farmers and should increase distribution channels to accommodate future production potential.
\end{abstract}

Keywords: Suitable farm size, Cost-benefit analysis, Pon Yang Kham Livestock Cooperative Limited, Fattening cattle

\section{Introduction}

Pon Yang Kham Livestock Cooperative Limited (PYK Coop) is located in Sakon Nakhon province, north-eastern Thailand. Since reporting commenced in 1980, PYK Coop has been attracting a lot of interest since it produces good quality beef products for the market. In 2017, PYK Coop consisted of 6,400 members, mainly from Sakon Nakhon province with some from neighbouring areas such as Nakhon Phanom province. Based on the available data from 2013-2017, the number of fattening cattle in PYK Coop is tending to rise. However, there is a decline in the number of fattening cattle being slaughtered (see Figure 1). In 2017, there were approximately 6,500 of 11,800 fattening cattle slaughtered, which accounted for $50 \%$ of the total fattening cattle. The members of PYK Coop suffer from financial problems. In addition, the increase in feeding expenses and prolonged feeding periods have increased annual costs to as high as THB 125.30 million.

In light of recent events in PYK Coop business management, it is becoming extremely difficult to ignore the inconsistency in the number of fattening cattle on the supply side and market demand. An objective of this study was to investigate the suitable farm size for Pon Yang Kham fattening cattle so that the farmer would have a reasonable investment. It is hoped that this research will contribute to a deeper understanding of the PYK Coop situation and can be used to guide policy for better product processing planning and marketing management. 


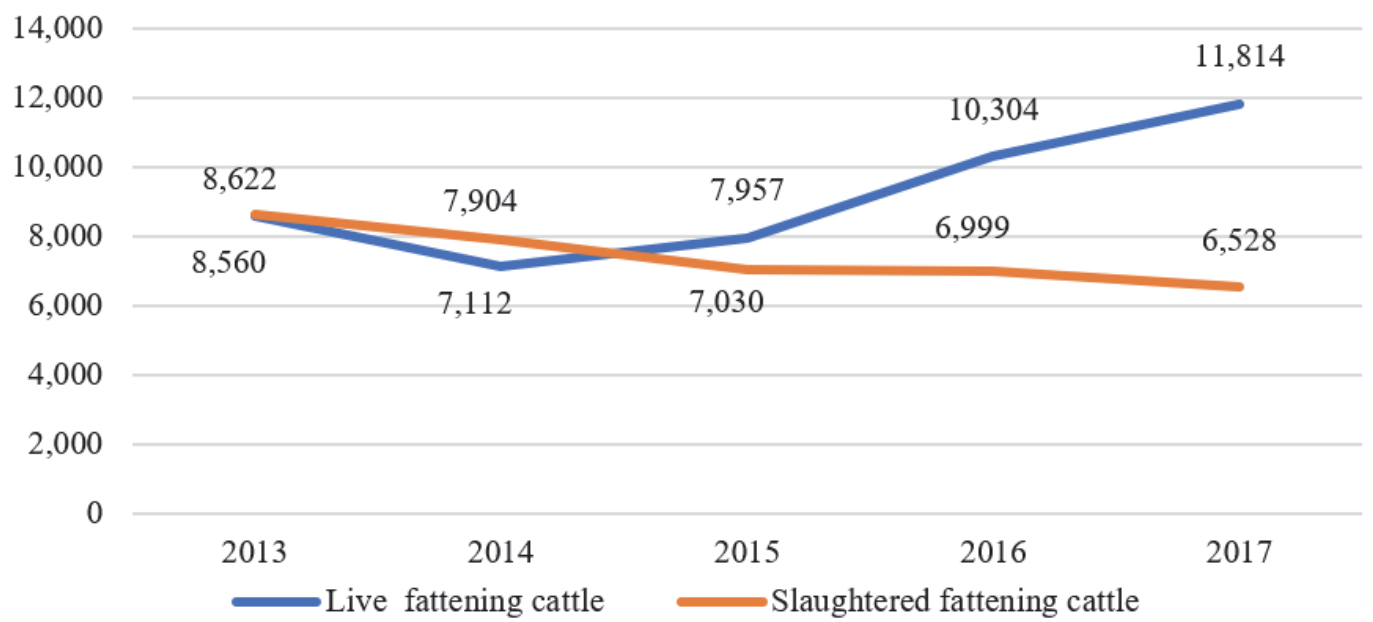

Figure 1. Number of live and slaughtered fattening cattle at PYK Coop

Source: PYK Coop Annual Report (2018)

\section{Method}

The study was based on cost-benefit analysis. Primary data were collected from 409members of PYK Coop out of a total of 6,428 members. The sample size (409) was estimated based on the formula proposed by Yamane (1967). The 409 farmers were classified according to 21 groups of cooperatives in Sakon Nakhon and Nakhon Phanom provinces. Primary data were collected using stratified proportional random sampling. All primary data were analysed using the cost-benefit analysis and classified by fattening cattle farm size. The three farm sizes were: small-sized farms with 1-5 cattle, medium-sized farms with 6-10 cattle and large-sized farms with more than 10 cattle.

Cost-benefit analysis in economics considers explicit costs and benefits that can be calculated in monetary terms. Costs can be classified into two types. First, a fixed cost is defined as an expense or cost that does not change with an increase or decrease in the number of goods or services produced or sold, such as land rent, land tax, agricultural equipment depreciation and long-term investments opportunity costs. Second, a variable cost is an expense that changes in proportion to production, such as calf and growing cattle, cattle feed, medical supplies, wages, fuel cost, utility cost, maintenance cost and short-term investment opportunity cost. The benefit is the value of the product or service produced from the investment and can be divided into a direct benefit from the value of the fattening cattle sold in 2018 and an indirect benefit from by-products such as cattle manure.

The total production cost is all expenses incurred from the production, i.e. cash and non-cash costs and can be written as (1):

$$
\text { Total Cost }=\text { Total Fixed Cost }+ \text { Total Variable Cost }
$$

The benefit from production includes all income that farmers receive from their production or from fattening cattle as shown in (2):

$$
\text { Total Benefit }=\text { Total Quantity } \times \text { Price }
$$

The gross return or the income over variable costs is the total benefit (2) deducted by the total variable costs and the net return or the income over total costs equal to total benefit (2) deducted by the total production cost (1).

$$
\begin{array}{ll}
\text { Gross Return } & =\text { Total Benefit (2) }- \text { Total Variable Cost } \\
\text { Net Return } & =\text { Total Benefit (2) }- \text { Total Cost (1) }
\end{array}
$$

The optimal farm size can be analysed using the break-even point of production from the cost-benefit analysis of PYK Coop farmers based on the three farm sizes using the formula:

$$
\text { Optimal Cattle }=\frac{\text { Average Fixed Cost }}{\text { Average Price - Average Variable Cost }}
$$

In Thailand, there are two types of beef cattle: 1) traditional farming or free ranch and 2) beef cattle production in livestock boxes which places an emphasis on a quality meat product. The total cost of beef cattle production under 
the free ranch approach is always lower than raising animals in barns. The main production cost of free ranch farming is the own labour cost which is a non-cash variable cost, so the total cash cost is low resulting in a profit or net return over the beef cattle in barns. The main production cost from cattle raising in barns is the feed or feed concentrate, which lowers the net return from growing calves and cattle (Mekdaeng et al., 2012; Wetchakama et al., 2017). PYK Coop members had a positive net income over the cash cost from fattening cattle with 11-12 months feeding of about THB 13,000-15,000 per head; however, considered on a total cash and non-cash cost basis they made a loss (Songserm, 2005; Niyompatama, 2011; Ngiewsrida, 2012; Kankaew, 2012). The problems associated with beef cattle farming are the limited sources of natural grass and a lack of grazing areas and the expense of concentrated feed, so beef cattle farming is possibly a part-time occupation to supplement income in the agriculture sector. On the other hand, the net benefit of raising cows to produce calves was positive at about THB 9,500 per head. (Yaemkong, 2016).

\section{Results and Discussion}

\subsection{General Data}

The majority of the 409 participants responded that they grew paddy rice as their primary occupation (92.91\%) and raised cattle as a supplementary occupation $(96.82 \%)$. The participants also reported that they had an average fattening cattle area of 0.12 hectares, with an average stable area of 0.08 hectares and average grassland of 0.33 hectares. All cattle areas were self-owned with an average price of THB 19,800/hectare. The household had an average of 4.35 members with 2.11 in agricultural labour. The average farmer had cattle experience of more than 10 years and received knowledge from PYK Coop and various educational institutions. Their source of investment funds was from the Bank for Agriculture and Agricultural Cooperatives.

\subsection{Pon Yang Kham Fattening Cattle}

The farmers had an average of 10.10 head of beef cattle, classified into bulls and cows (3.51 head), calves and growing cattle (2.24 head) and fattening cattle (4.35 head). There were 142 farms $(34.72 \%)$ classified as small that had no more than five head of cattle per farm, while 120 farms (29.34\%) were classified as medium-sized and had 6-10 head per farm. The remaining farms (147 or 35.94\%) were large-sized that had more than 10 head per farm. The average numbers of fattening cattle per farm size were 2.21, 3.64 and 6.39, respectively. A majority of the farmers $(80.68 \%)$ bought their cattle from the community market or neighbourhood, and almost half of the participants $(47.92 \%)$ bred the cattle themselves.

A majority of the participants had stables for fattening cattle in the house area $(94.62 \%)$. A majority of the stables were built from partial wood and cement with a metal sheet roof, with $57.21 \%$ of the participants having improved the cattle area from the wooden stables with an earthen floor to standard stables on a concrete floor. The stables had a feed trough, used tires for drinking water storage and had other equipment such as mowers, water pumps, weight scales, water tanks, food mixers and grinding machines.

The farmers started feeding concentrated food to the fattening cattle when the cattle were aged on average 21.53 months, or when each animal weighed about 369.85 kilograms. The feed for the fattening cattle consisted of concentrated food, fodder, grass, rice bran, cassava pulp and molasses with average usage quantities of 4.03, 6.85, $5.20,3.28,3.58$ and 1.04 kilogram per day per head, respectively. The concentrated feed and molasses were bought from PYK Coop with average prices of THB 8.74 and 6.20 per kilogram, respectively. The fodder, grass, rice bran and cassava pulp were bought from the local market with average price of THB 1.39, 2.06, 6.86 and 2.18 per kilogram, respectively. All farmers had veterinary health checks of their cattle twice a year by veterinary and the medical service was provided by the cooperative, costing THB 303.01 per service per head.

\subsection{Production Costs of Pon Yang Kham Fattening Cattle}

Table 1 presents the production costs for Pon Yang Kham fattening cattle. The total production cost for PYK Coop was THB 317,465.01 per farm per year, classified into fixed costs (5.44\%) and variable costs (94.56\%). The fixed costs comprised land use opportunity cost, housing and equipment depreciation and the long-term opportunity cost accounting for $0.58 \%, 4.46 \%$, and $0.40 \%$, respectively. The top-3 highest variable costs were cattle feed, labour cost and the cost of calves or growing cattle accounting for $37.12 \%, 26.57 \%$, and $26.11 \%$, respectively. The other variable costs included short-term opportunities cost (4.75\%). However, a majority of the farmers used their own labour for fattening cattle, resulting in a non-cash cost. Thus, the highest cash cost for the fattening animals was the cost of cattle feed and the cost of the calves and growing cattle.

The total benefit from Pon Yang Kham fattening cattle was THB 274,836.43 per farm per year and could be classified into a direct benefit from the sale of fattening cattle (THB 247,154.03 per farm per year) and an indirect benefit from the sale of cattle manure (THB 27,682.40 per farm per year). Overall, the net return from Pon Yang Kham fattening cattle 
showed income in excess of the cash cost of THB 80,686.33 per farm per year. The income over variable costs was THB $-25,349.45$ per farm per year, while the income over the total cost was THB $-42,628.58$ per farm per year. Thus, the profit per cattle calculated as the income over the cash cost was THB 25,984.81 per head per year and the income over variable costs was THB -8,163.72 per head per year resulting in income over the total cost of THB $-13,728.42$ per head per year. Although the net return of Pon Yang Kham fattening cattle suggested it was worth investing because its net income over the total cost was negative, the income over the cash cost was positive. This suggested that fattening cattle could be a supplementary occupation with a share of inputs with other activities on the farm.

Table 1. Costs and benefits of Pon Yang Kham fattening cattle in 2018

Unit: THB per year

\begin{tabular}{|c|c|c|c|}
\hline List & Cash & Non-cash & Total \\
\hline \multicolumn{4}{|l|}{ 1. Variable cost } \\
\hline \multicolumn{4}{|l|}{ 1.1 Material for planting grass } \\
\hline - Seed & 258.85 & - & 258.85 \\
\hline - Organic fertilizers & 848.67 & - & 848.67 \\
\hline - Chemical fertilizers & 525.83 & - & 525.83 \\
\hline \multicolumn{4}{|l|}{ 1.2 Cattle feed } \\
\hline - Concentrate & $45,010.39$ & - & $45,010.39$ \\
\hline - Fodder & $12,195.94$ & - & $12,195.94$ \\
\hline - Grass & - & $13,687.93$ & $13,687.93$ \\
\hline - Rice bran & $28,759.16$ & - & $28,759.16$ \\
\hline - Molasses & $8,212.95$ & - & $8,212.95$ \\
\hline - Cassava pulp & $9,980.19$ & - & $9,980.19$ \\
\hline \multicolumn{4}{|l|}{ 1.3 Labour } \\
\hline \multicolumn{4}{|l|}{ 1.3.1 Grassland management } \\
\hline - Grassland preparation & 882.20 & 474.73 & $1,356.93$ \\
\hline - Soil ploughing & 836.99 & 408.34 & $1,245.33$ \\
\hline - Grassland general care & - & $10,978.06$ & $10,978.06$ \\
\hline - Grazing & - & $23,550.69$ & $23,550.69$ \\
\hline \multicolumn{4}{|l|}{ 1.3.2 Fattening cattle } \\
\hline - Feed preparation & - & $13,811.25$ & $13,811.25$ \\
\hline - Feeding & - & $13,813.23$ & $13,813.23$ \\
\hline - Cattle general care & - & $11,814.84$ & $11,814.84$ \\
\hline - Cattle cleaning & - & $7,789.21$ & $7,789.21$ \\
\hline 1.4 Calf and growing cattle & $82,898.50$ & - & $82,898.50$ \\
\hline \multicolumn{4}{|l|}{1.5 Other costs } \\
\hline 1.5.1 Veterinary and medical & $1,060.91$ & - & $1,060.91$ \\
\hline 1.5.2 Electricity & 255.78 & - & 255.78 \\
\hline 1.5.3 Water & 125.07 & - & 125.07 \\
\hline 1.5.4 Fuel & 521.73 & - & 521.73 \\
\hline 1.5.5 Equipment maintenance & 549.83 & - & 549.83 \\
\hline 1.5.6 Transportation & $1,227.10$ & - & $1,227.10$ \\
\hline 1.6 Short-term opportunity cost & & $9,707.51$ & $9,707.51$ \\
\hline Total variable costs & $194,150.10$ & $106,035.78$ & $300,185.88$ \\
\hline
\end{tabular}


Table 1. (Cont.)

\begin{tabular}{|c|c|c|c|}
\hline List & Cash & Non-cash & Total \\
\hline \multicolumn{4}{|l|}{ 2. Fixed cost } \\
\hline 2.1 Land using opportunity cost & - & $1,845.89$ & $1,845.89$ \\
\hline \multicolumn{4}{|l|}{ 2.2 Housing and equipment depreciation } \\
\hline - Housing/livestock boxes & - & $4,637.13$ & $4,637.13$ \\
\hline - Food storage/barn & - & $1,851.46$ & $1,851.46$ \\
\hline - Food mixer or grinder machine & - & $4,508.00$ & $4,508.00$ \\
\hline - Water well/pond & - & 278.80 & 278.80 \\
\hline - Pump machine & - & 923.78 & 923.78 \\
\hline - Mower & - & 835.22 & 835.22 \\
\hline - Other equipment & - & $1,124.56$ & $1,124.56$ \\
\hline 2.3 Long-term opportunity cost & - & $1,274.30$ & $1,274.30$ \\
\hline Total fixed costs & - & $17,279.13$ & $17,279.13$ \\
\hline Total costs & $194,150.10$ & $123,314.91$ & $317,465.01$ \\
\hline \multicolumn{4}{|l|}{ 3. Benefit } \\
\hline 3.1 Fattening cattle & $247,154.03$ & - & $247,154.03$ \\
\hline 3.2 Fattening cattle manure & $27,682.40$ & - & $27,682.40$ \\
\hline Total Benefits & $274,836.43$ & - & $274,836.43$ \\
\hline \multicolumn{4}{|l|}{ 4. Net return } \\
\hline \multicolumn{4}{|l|}{ 4.1 Net return per farm (THB/farm/year) } \\
\hline - Income over cash cost & & & $80,686.33$ \\
\hline - Income over variable cost & & & $-25,349.45$ \\
\hline - Income over total cost & & & $-42,628.58$ \\
\hline \multicolumn{4}{|c|}{ 4.2 Net return per cattle (THB/head/year) } \\
\hline - Income over cash cost & & & $25,984.81$ \\
\hline - Income over variable cost & & & $-8,163.72$ \\
\hline - Income over total cost & & & $-13,728.42$ \\
\hline
\end{tabular}

Source: from survey

\subsection{Suitable Farm Size for Pon Yang Kham Fattening Cattle}

The suitable farm size for Pon Yang Kham fattening cattle was analysed from the cost-benefit analysis of the three farm sizes, as shown in Table 2. The total production cost was THB 134,698.30, 236,711.40 and 482,472.08 per farm per year for the small-sized, medium-sized and large-sized farms, respectively. The overall benefit from fattening cattle in each size was THB 127,840.14, 233,795.83 and 450,335.37 per farm per year, respectively. Hence, the net return based on income over the cash cost was THB 62,536.27, 92,924.00 and 152,871.67 per farm per year or THB 40,548.63, 34,846.50 and 30,741.63 per head per year. 
Table 2. Costs and benefits of Pon Yang Kham fattening cattle classified by farm size in 2018

Unit: THB per year

\begin{tabular}{lllll}
\hline List & Small & Medium & Large & Total \\
\hline 1. Variable cost & & & & \\
1.1 Material for planting grass & 516.94 & 992.06 & $3,690.42$ & $1,633.35$ \\
1.2 Cattle feed & $52,492.21$ & $93,840.80$ & $201,491.83$ & $117,846.56$ \\
1.3 Labour & $49,596.22$ & $67,442.66$ & $127,238.66$ & $84,359.54$ \\
1.4 Calves and growing cattle & $16,903.68$ & $51,519.64$ & $104,826.48$ & $82,898.50$ \\
1.5 Other costs & $2,163.47$ & $3,022.30$ & $5,574.33$ & $3,740.42$ \\
1.6 Short-term opportunity cost & $3,265.19$ & $7,043.59$ & $14,873.19$ & $9,707.51$ \\
\hline Total variable costs & $124,937.73$ & $223,861.06$ & $457,694.91$ & $300,185.88$ \\
\hline 2. Fixed cost & & & & \\
2.1 Land using opportunity cost & $2,258.45$ & $2,441.67$ & $2,712.24$ & $1,845.89$ \\
2.2 Housing and equipment depreciation & $7,502.12$ & $10,408.68$ & $22,064.91$ & $14,158.95$ \\
2.3 Long-term opportunity cost & 619.44 & 859.43 & $1,821.87$ & $1,274.30$ \\
\hline Total fixed costs & $9,760.57$ & $12,850.34$ & $24,777.17$ & $17,279.13$ \\
\hline Total costs & $134,698.30$ & $236,711.40$ & $482,472.08$ & $317,465.01$ \\
\hline 3. Benefit & & & & \\
3.1 Fattening cattle & $119,688.73$ & $212,871.67$ & $398,269.39$ & $247,154.03$ \\
3.2 Fattening cattle manure & $8,151.41$ & $20,924.17$ & $52,065.99$ & $27,682.40$ \\
\hline Total benefits & $127,840.14$ & $233,795.83$ & $450,335.37$ & $274,836.43$ \\
\hline 4. Net benefit & & & & \\
4.1 Net return per farm (THB/farm/year) & & & & \\
- Income over cash cost & $62,536.27$ & $92,924.00$ & $152,871.67$ & $80,686.33$ \\
- Income over variable cost & $2,902.41$ & $9,934.77$ & $-7,359.53$ & $-25,349.45$ \\
- Income over total cost & $-6,858.16$ & $-2,915.57$ & $-32,136.71$ & $-42,628.58$ \\
4.2 Net benefit per cattle (THB/head/year) & & & & \\
- Income over cash cost & $40,548.63$ & $34,846.50$ & $30,741.63$ & $25,984.81$ \\
- Income over variable cost & $1,881.93$ & $3,725.54$ & $-1,479.96$ & $-8,163.72$ \\
- Income over total cost & $-4,446.84$ & $-1,093.34$ & $-6,462.51$ & $-13,728.42$ \\
\hline Source: from survey & & & & \\
\hline
\end{tabular}

Source: from survey

Table 3. Suitable number of Pon Yang Kham fattening cattle classified by farm size

Unit: THB per farm

\begin{tabular}{lllll}
\hline List & Small & Medium & Large & Total \\
\hline 1. Variable Cost (THB/farm/year) & $124,937.73$ & $223,861.06$ & $457,694.91$ & $300,185.88$ \\
2. Fixed Cost (THB/farm/year) & $9,760.57$ & $12,850.34$ & $24,777.17$ & $17,279.13$ \\
3. Total Cost (THB/farm/year) & $134,698.30$ & $236,711.40$ & $482,472.08$ & $317,465.01$ \\
4. Total Benefit (THB/farm/year) & $127,840.14$ & $233,795.83$ & $450,335.37$ & $274,836.43$ \\
5. Price (THB/head) & $77,606.39$ & $79,826.88$ & $80,089.74$ & $79,595.28$ \\
6. Break-Even Point (Head) & -0.21 & -0.09 & -0.07 & -0.08 \\
7. Suitable Cattle (Head) & 1.34 & 2.58 & 4.91 & 3.03 \\
\hline
\end{tabular}

Source: from survey

The results suggested that the fattening cattle decision maker can plan from a break-even point analysis and considering both fixed inputs and variable inputs together with the market price or the average price that farmers receive from the cooperative. From Table 3, the small-sized farm which no more than five head of cattle and feeding 1.54 fattening cattle, based on the break-even point analysis for fattening cattle should reduce the number of fattening cows to only 1.34 . The medium-sized farm with 6-10 cattle per farm and 2.67 fattening cattle should reduce the fattening cattle to 2.58 . The large-sized farm with more than 10 head per farm with 4.97 fattening cattle should reduce the number of fattening cattle slightly to 4.91. To sum up, on average, a farmer who was a PYK Coop member should raise 3.03 head of fattening cattle per farm. 
The results from the cost-benefit analysis classified by farm size (Table 2) showed the net return over the cash cost for a large-sized farm was THB 152,871.67 per farm per year which was higher than for the medium- and smallsized farms with values of THB 92,924.00 and 62,536.27 per farm per year, respectively. Although the small farm had the lowest net return per farm, the value of return per cattle head was higher than the medium and large farm.

The proportion of total income to cash costs for the small-sized farms was 1.96. In other words, fattening cattle investment would double the revenue, followed by medium- and large-sized farms with proportions of 1.66 and 1.51 , respectively. However, if considering the ratio of total benefits to total costs, all farms regardless of their size, had total costs more than total benefits. For medium-sized farms this proportion was nearly 1 , so total costs equalled total benefits and so was regarded as the most suitable farm size, compared to the other two sizes. The large farm had double the cost of cattle feed than the other farms and had greater labour costs in farming cattle and planting grassland. In contrast, the small farm recorded a lot of the fixed value from the standard livestock boxes and agricultural machinery and equipment investment. In summary, Pon Yang Kham fattening cattle should be a part-time occupation rather than being developed into a main career or large-scale production.

\section{Conclusion}

The analysis of the suitable farm size for Pon Yang Kham fattening cattle aimed to find the break-even point for finishing cattle from a cost-benefit analysis that could reflect the production decisions from the use of production factors and the received price. In this study classifying the return by farm size, the results showed that the net income over the cash cost of the large-sized farms was higher than for the other two sizes (medium- and smallsized farms, respectively). In contrast, the net return per cattle head on the small farm was higher than for the other two (medium- and large-sized farms, respectively. These reflected that even though the large-sized farm received the highest net return, the small-sized farm had a greater net return per head of cattle than the large-sized farm because of the high cost of variable inputs such as feed concentrate and labour costs. The optimal feedlot numbers for beef cattle on the small-, medium- and large-sized farms were 1.34, 2.58 and 4.91 head per year or overall it was 3.03 head per year. Consequently, PYK Coop should set a target number of beef cattle for members of not over 10 with 3 fattening cattle, which would make a suitable cattle investment that would be profitable.

These results can be used as guidelines for PYK Coop to manage and encourage their farmers to feed their beef cattle to reduce the risk and the uncertainty of business operations, as follows:

1. PYK Coop should help the member to have the cattle, not over ten beef cattle and feeding fattening cattle three head per year for the appropriated production cost and the farmer will gain the cash benefit.

2. The highest cost of Pon Yang Kham fattening cattle production was the cost of the cattle and secondly the concentrate feed (26.11 and $14.18 \%$, respectively, of the total cost) and these were the factors associated with making a loss form cattle farming. The farmer should reduce unnecessary expenses by breeding their own calves which could reduce the growing cattle costs by THB 19,057.13 per head. Alternatively, they should lower their feed cost by using appropriate feeding formulae for the growing cattle.

\section{Acknowledgments}

This research "The Optimal Farm Size Analysis of Pon Yang Kham Beef Cattle Project" was supported by funding through a scholarship from The Research and Academic Services Division, the Office of Chalermphrakiat Sakon Nakhon Province campus.

\section{References}

Kankaew, C. (2012). Cow-Calf Production of Farmers under the Pon Yang Khram Livestock Cooperatives, Ltd. Master of Science (Animal Science), Graduate School, Kasetsart University.

Mekdaeng, K., Kantanamalakul, C., \& Pothidee, A. (2012). The Production Management of Beef Cattle in Barns and Free Ranch at Muang District, Kanchanaburi Province. The 2nd STOU Graduate Research Conference. Nonthaburi.

Ngiewsrida, C. (2012). Financial Value Investments Analysis of Pon Yang Khram Livestock Cooperative Limited. Master of Economics (Business Economics), Graduate School, Khon Kaen University.

Niyompatama, J. (2011). Factors Affecting the Production of High-Quality Cattle of the Member of Pon Yang Khram Livestock Cooperatives, Ltd. Master of Arts (Cooperative Economics), Graduate School, Kasetsart University.

Pon Yang Khram Livestock Cooperative Limited. (2018). The Annual Report 2017.

Songserm, W. (2005). A Financial Analysis of Cost and Return on Fattened Cattle Farming Investment of the 
Farmers as a Member of Phonyangkham Livestock Cooperative Limited in Amphoe Muang Changwat Sakonnakhorn. Master of Arts (Agribusiness), Graduate School, Kasetsart University.

Wetchakama, N., Chinnasaen, T., \& Polviset, W. (2017). Beef Cattle Production and Management in Barns and

Free Ranch Farming of farmers in Borabue District, Maha Sarakham Province. Khon Kaen Agriculture Journal, 45 SUPPL. 1, 1146-1482.

Yaemkong, S. (2016). Beef Production Cost and Returns of Farmers in Wat Bot and Phrom Phiram District, Phitsanulok Province. Journal of Agriculture, 32(3), 401-407.

\section{Copyrights}

Copyright for this article is retained by the author(s), with first publication rights granted to the journal.

This is an open-access article distributed under the terms and conditions of the Creative Commons Attribution license (http://creativecommons.org/licenses/by/4.0/). 